UCRL-JC-129302

PREPRINT

\title{
Recent Advances and Challenges for Diode-Pumped Solid-State Lasers as an Inertial Fusion Energy Driver Candidate
}

\author{
S. A. Payne, R. J. Beach, C. Bibeau, C. A. Ebbers, M. A. Emanuel, \\ E. C. Honea, W. F. Krupke, C. D. Marshall, C. D. Orth, H. T. Powell, \\ K. I. Schaffers, J. A. Skidmore, S. B. Sutton
}

This paper was prepared for submittal to the 17th IEEE/NPSS Symposium on Fusion Engineering San Diego, CA October 6-10, 1997

December 23, 1997

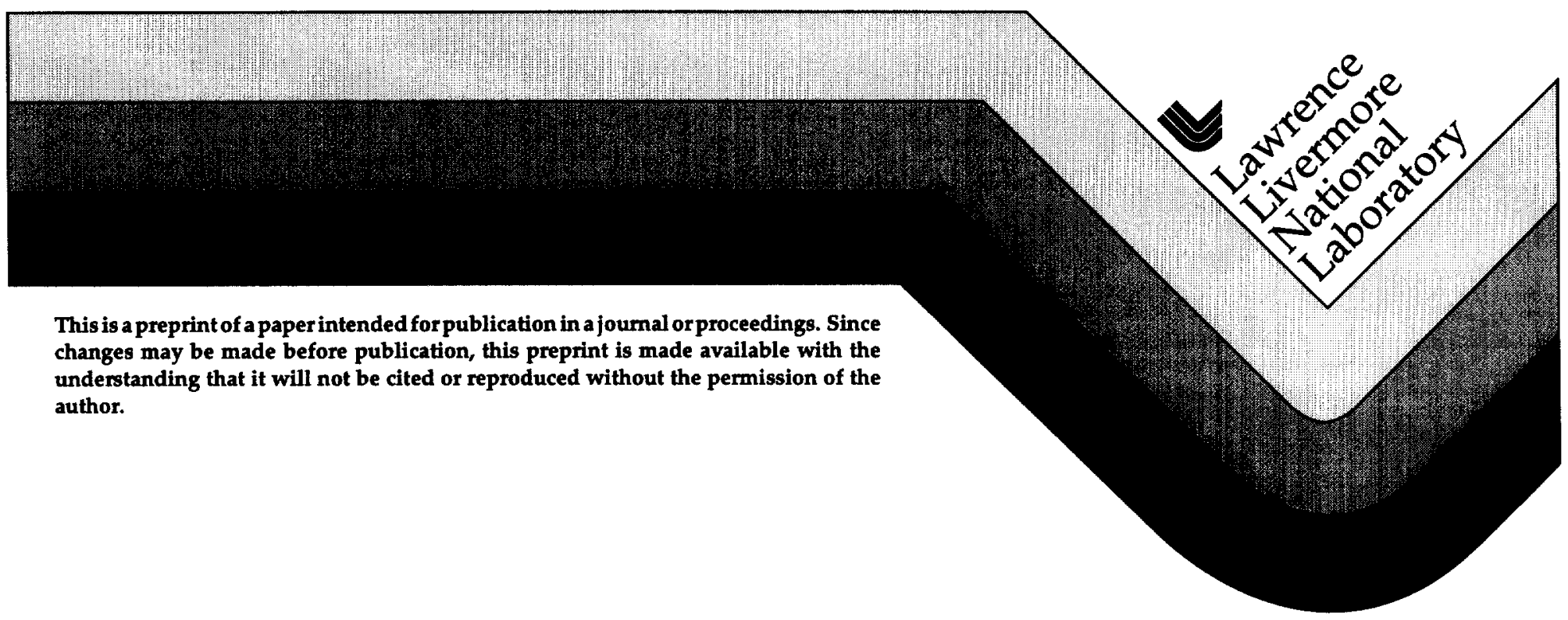




\section{DISCLAIMER}

This document was prepared as an account of work sponsored by an agency of the United States Government. Neither the United States Government nor the University of California nor any of their employees, makes any warranty, express or implied, or assumes any legal liability or responsibility for the accuracy, completeness, or usefulness of any information, apparatus, product, or process

disclosed, or represents that its use would not infringe privately owned rights. Reference herein to any specific commercial product, process, or service by trade name, trademark, manufacturer, or otherwise, does not necessarily constitute or imply its endorsement, recommendation, or favoring by the United States Government or the University of California. The views and opinions of authors expressed herein do not necessarily state or reflect those of the United States Government or the University of California, and shall not be used for advertising or product endorsement purposes. 


\title{
Recent Advances and Challenges for Diode-Pumped Solid-State Lasers as an Inertial Fusion Energy Driver Candidate*
}

\author{
S A. Payne, R J. Beach, C. Bibeau, C. A. Ebbers, M. A. Emanuel, E. C. Honea, W. F. Krupke, \\ C. D. Marshall, C. D. Orth, H. T. Powell, K. I. Schaffers, J. A. Skidmore, and S. B. Sutton \\ Lawrence Livermore National Laboratory \\ University of California \\ P.O. Box 808, L-441 \\ Livermore, California 94550
}

\begin{abstract}
We discuss how solid-state laser technology can serve in the interests of fusion energy beyond the goals of the National Ignition Facility (NIF), which is now being constructed to ignite a deuterium-tritium target to fusion conditions in the laboratory for the first time. We think that advanced solid-state laser technology can offer the repetition-rate and efficiency needed to drive a fusion power plant, in contrast to the single-shot character of NIF. As discussed below, we propose that a gascooled, diode-pumped $\mathbf{Y b}: S-F A P$ laser can provide a new paradigm for fusion laser technology leading into the next century.
\end{abstract}

\section{INTRODUCTION}

Since the original suggestion by Emmett, Krupke and Trenholme in 1983 [1] that diode pump sources would one day offer the requisite cost and efficiency to be deployed in a solid-state laser used for inertial fusion energy, a detailed study conducted by Orth et al. [2] has revealed that laser efficiencies of $>10 \%$ are reasonable to anticipate for a wellengineered diode-pumped solid-state fusion laser even on the basis of today's technology. The study also showed that the achievable target gain is indeed the most crucial parameter impacting the cost-of-electricity (COE), depending on the successes of the indirect, direct, or the fast-ignitor options (with the COE being between 5.5 - 8.6 cents/ $\mathrm{kWhr}$ ). We have recently built the first small joule-level free-lasing module, scientifically integrating the key technologies of gas-cooling, laser diode arrays, and Yb:S-FAP laser crystals [3,4]. Fig. 1a depicts a gas-cooled slab head, including the diode array. Figs. $1 \mathrm{~b}$ and $\mathrm{Ic}$ show the measurements of the heat flux removal and the energy extraction in a long-pulse oscillator: On the basis of this small testbed, we were able to convince ourselves that the technology was ready to move into an early engineering stage entailing a prototypical 100 joule solidstate laser that is $1 / 10$ scale of one beamlet (delivering $1 \mathrm{~kJ}$ ), and $1 / 150$ scale of one beamline $(15 \mathrm{~kJ})$ - these three steps in laser development have been dubbed the Mercury, Venus, and Terra lasers. Ultimately, about 300 beamlines will be needed in the power plant design (Helios). One of the critical elements of this vision is that the Mercury, Venus and Terra lasers will prove to be useful in the near-term as targetshooters relevant to high-gain target physics and chamber technology development before inertial fusion energy becomes a reality.

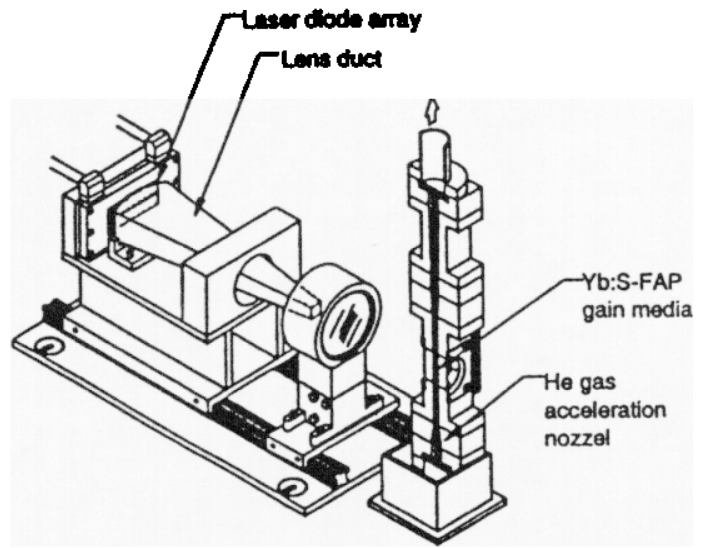

Fig. 1a. Schematic drawing of joule-level diode-pumped gascooled Yb:S-FAP laser head.

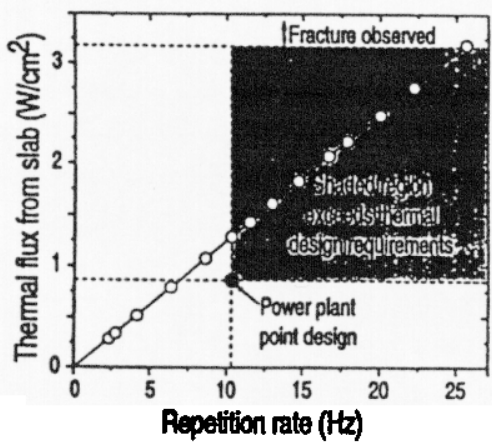

Fig. 1b. Measured heat flux removal from the diode-pumped Yb:S-FAP slab using 0.1 Mach flow of helium in $1 \mathrm{~mm}$ channels.

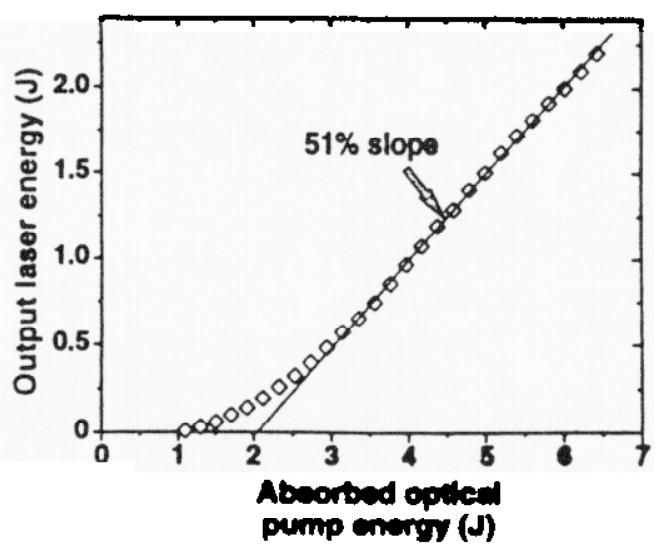

Fig. Ic. Laser output, with diode pump Yb:S-FAP head operating as simple long-pulse oscillator. 


\section{MERCURY LASER TECHNOLOGY}

\section{A. Laser Architecture}

A conceptual drawing of the Mercury laser system is depicted in Fig. 2, where the diode arrays and the gas-cooled laser heads are shown. The laser is designed to operate at $10 \mathrm{~Hz}$ with $10 \%$ efficiency, generating more than 100 joules at the $1.047 \mu \mathrm{m}$ fundamental wavelength of the laser; see Fig. 3.

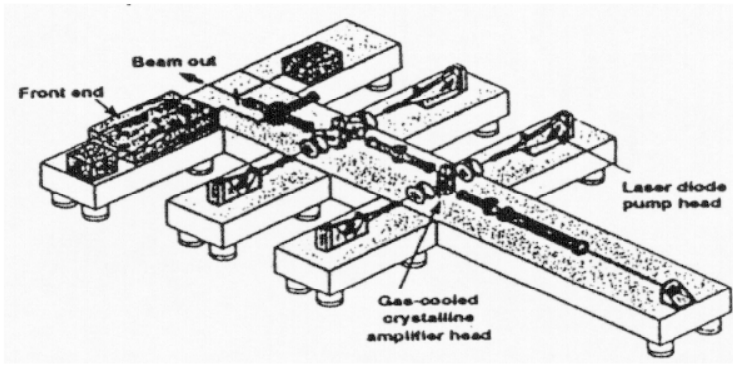

Fig. 2 Schematic drawing of Mercury Laser, depicting the main elements of the system.

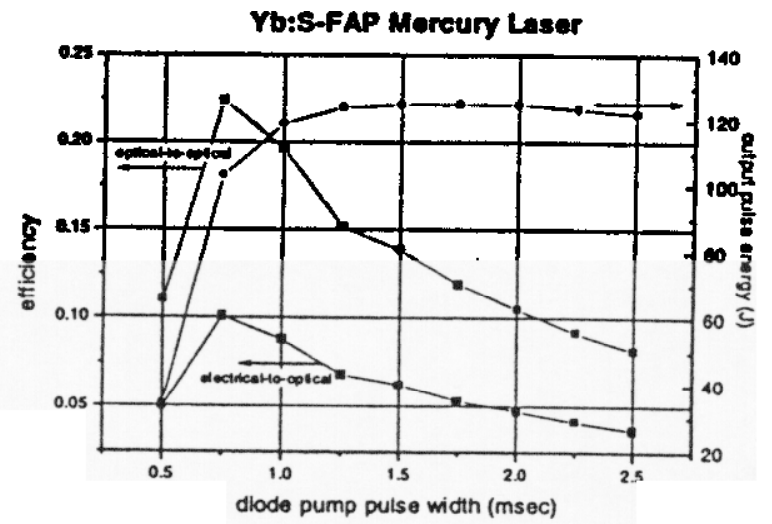

Fig. 3 Output energy of the diode-pump gas-cooled Yb:SFAP Mercury Laser as a function of pump time.

Like NIF, the architecture is based on a four-pass system, where the beam is image-relayed to minimize diffractive losses and intensity modulation. The diode arrays are seen to be pumping the laser heads from both ends through an angled dichroic beam splitter. The injected energy from the front-end is about $10 \mathrm{~mJ}$, and the single-pass small-signal gain of the system is 4.2 nepers. The gas-cooled heads are fitted with seven slabs of $\mathrm{Yb}: S-F A P$, each embedded in a vane for flow control (see Figs $4 \mathrm{a}$ and $4 \mathrm{~b}$ ). The required gas-flow will be at 0.1 Mach using helium to remove $1.3 \mathrm{~W} / \mathrm{cm}^{2}$ of thermal flux. The shape of the vanes have been designed to avoid eddy currents, which could lead to vibrations.

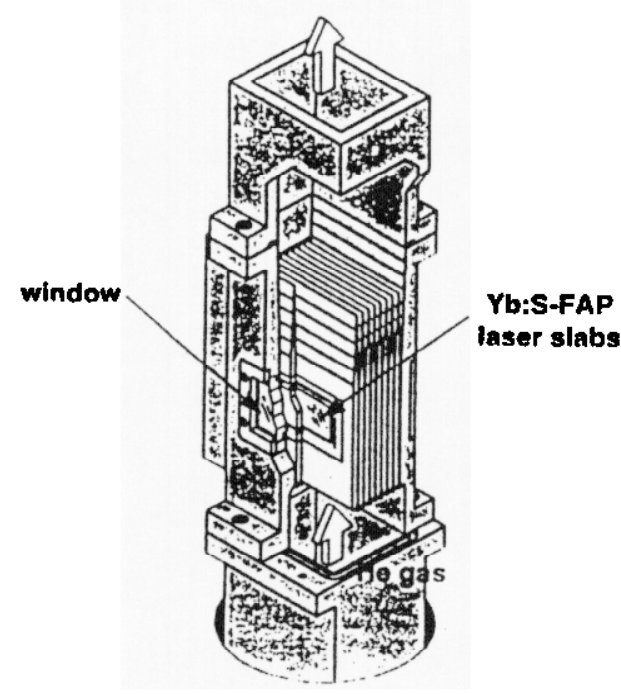

Fig. 4a. Schematic of gas-cooled head of Mercury Laser illustrating 7 vanes embedded with $\mathrm{Yb}: \mathrm{S}$-FAB.

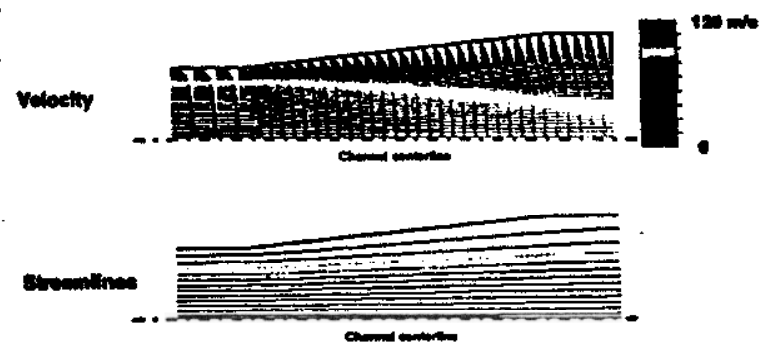

Fig. 4b. Calculated flow of helium over individual vane structure.

\section{B. Diode Arrays}

We have a devised a heatsink package for the Mercury laser that minimizes cost, while maximizing diode amay performance and brightness. The package involves a $\mathrm{BeO}$ heatsink in which InGaAs laser-diode bars are precisely mounted, and a micro-lens array is aligned to minimize the angular divergence along the fast axis; the pitch is 10 bars $/ \mathrm{cm}$. The data in Figs. 5a and $5 \mathrm{~b}$ reveals that we have been able to operate a 40 bar array at $4 \mathrm{~kW}$ peak power, and that the angular divergence is $40 \mathrm{mrad}$ versus $150 \mathrm{mrad}$ along the fast (i.e., micro-lensed) and slow axes of the module (which determines the brightness). In a qualitative sense, the pump intensity at the Yb:S-FAP crystal slab is mostly dictated by the fundamental parameters of the $\mathrm{Yb}$ :S-FAP gain medium used in Mercury (i.e. the pumped extraction saturation fluences). Since we need to concentrate the light by 15 to $10 \mathrm{~kW} / \mathrm{cm}^{2}$ (from $-0.7 \mathrm{~kW} / \mathrm{cm}^{2}$ at the output of the array), the diode brightness is the key parameter impacting the 
intensity that can be produced at the Yb:S-FAP laser gain media. In other words, the brightness directly determines the delivery efficiency of the diode light from the array into the gas-cooled crystals. This efficiency is calculated to be $81 \%$ for the Mercury laser.

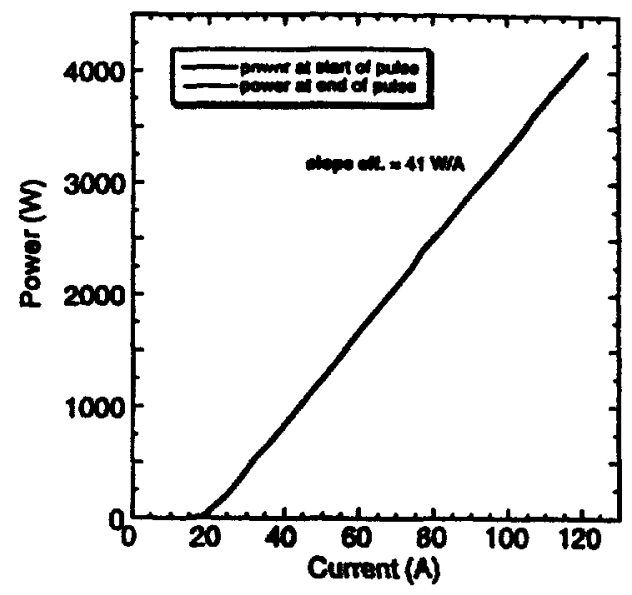

Fig. 5a. 40-bar diode array output power as a function of drive current for $1 \mathrm{msec}$ pulses.

\section{Diode Divergence}

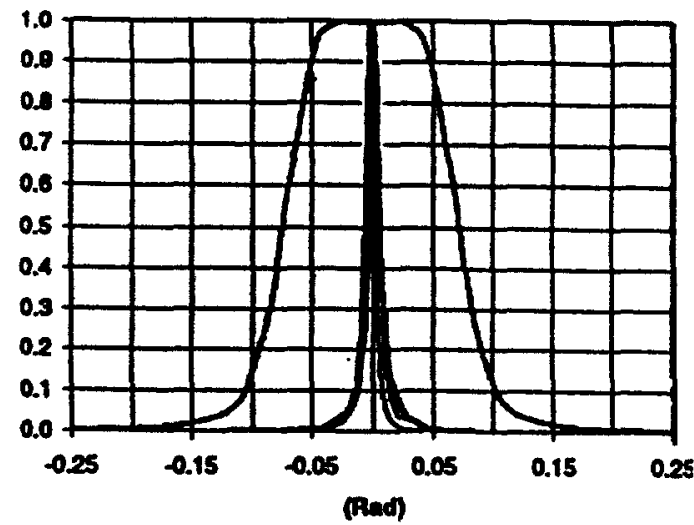

Fig. Sb. Angular characteristic of diode array output inversely proportional to brightness.

\section{Yb:S-FAP Laser Crystals}

Several years ago we performed a systematic search of potential gain media that could be of utility to a nextgeneration fusion laser $[5,6]$. We then down-selected what we believed to the best known candidate among the 50 possibilities that we examined, which proved to be Yb-doped $\mathrm{Sr}_{5}\left(\mathrm{PO}_{4}\right)_{3} \mathrm{~F}$ or $\mathrm{Yb}: \mathrm{S}-\mathrm{FAP}$. This selection resulted from a combined assessment of properties such as the gain cross section, crystal growth, thermomechanical parameters, and storage time, and was judged superior for the fusion laser application in particular. The size of the crystals in our design is $3 \times 5 \mathrm{~cm}$, where the rectangular shape is chosen to equalize the tendency for parasitic oscillations in the two dimensions based on the anisotropic nature of the crystal. Currently, we have grown crystals with diameters as large as $5 \mathrm{~cm}$, although occlusions known as core defects are found to be concentrated near the center of the crystal boule. We have determined that the core defects arise from a rising deficiency of $\mathrm{SrF}_{2}$ that increases during the 4-6 day growth run because of evaporation. In response to this situation, we are currently investigating ways to add more $\mathrm{SrF}_{2}$ during growth and to reduce evaporation by controlling the temperature gradients in the heated crucible.

\section{DRIVER FOR ADVANCED EXPERIMENTS AND INERTIAL FUSION ENERGY}

The Mercury laser should be viewed as the first small but significant step toward the emergence of a new technology paradigm for fusion laser drivers. The flashlamp-pumped Nd:glass lasers used since the 1970 s have proved invaluable for unraveling the plasma physics and target issues relating to achieving fusion ignition. The success of the solid state laser follows from the fact that this approach is inherently "engineerable," and able to meet the demands on pulseshaping, wavelength, power balance, etc. imposed by the target physics. We have learned a great deal about the laser physics and engineering of solid state lasers during this time period, such as beam propagation, nonlinear and linear distortion, optical fabrication techniques, pulse shaping, coherence control, and optical damage thresholds. It is worth emphasizing that much of the basic physics and engineering principles developed for convectively-cooled, flashlamppumped Nd:glass lasers can be applied to the turbulentlycooled, diode-pumped Yb:S-FAP lasers that we are proposing. In other words, the advanced laser designs discussed herein are strongly predicated on the progress made during the last two docades. The timeline of Fig. 6, plotting the energy of the flashlamp-pumped Nd:glass fusion lasers built (or planned) at Lawrence Livermore National Laboratory [7], also includes a hypothetical timeline for diode-pumped solid-state lasers. The $15 \mathrm{~kJ}$ Terra laser is "Nova-class" and is envisioned to be a companion facility to NIF for pre-staging experiments and developing diagnostics. Terra laser can provide shots-ondemand, in contrast to the 4 hour turnaround anticipated for NIF. It is noteworthy that the high repetition-rate capability $(10 \mathrm{~Hz})$ is not a major cost center (i.e. gas-cooling equipment is a minor expense compared to the diode arrays). So the 15 kJ Terra laser can be operated flexibly depending on the experimenter requirements: e.g. $10 \mathrm{~Hz}, 1 \mathrm{~Hz}, 0.01 \mathrm{~Hz}$, possibly entailing multiple target chambers, etc. 


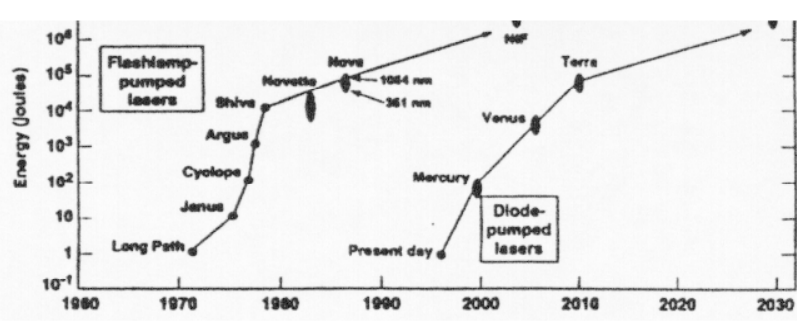

Fig. 6. Proposed time line for diode-pumped Yb:S-FAP solidstate lasers superimposed on progress in flashlamp-pump Nd:glass solid state lasers.

The concept of an inertial fusion energy (IFE) power plant is thought to require a $\sim 4 \mathrm{MJ}$ laser driver, one beamline of which is sketched in Fig. 7. In a sense, the laser driver is one of the more developed technologies of IFE, since other areas such as the survivability of the "final-optic" (separating the laser from the target chamber), and the "first-wall" (which encounters the $x$-ray and target debris following the implosion) have not yet been resolved. It has previously been suggested that heated fused silica could serve in the role of the final optic by rapidly annealing away the intrinsic defects created by the neutron/gamma flux. Some of our experiments have supported this notion, and the balance between defect creation (oxygen-deficient centers and $\mathrm{E}^{\prime}$ centers) and their thermal annealing is calculated in Fig. 8 for a dose at 50 $\mathrm{kRad} / \mathrm{sec}$. Other pressing issues involve chamber clearing and target fabrication/ injection as well as the need for beam smoothness and bandwidth on the laser driver (where electronbeam pumped $\mathrm{KrF}$ lasers may offer some advantages over solid state lasers with regard to these issues [9]). The success of laser-IFE requires the resolution of the fusion physics, laser driver, chamber recovery and survivability, and economic issues.

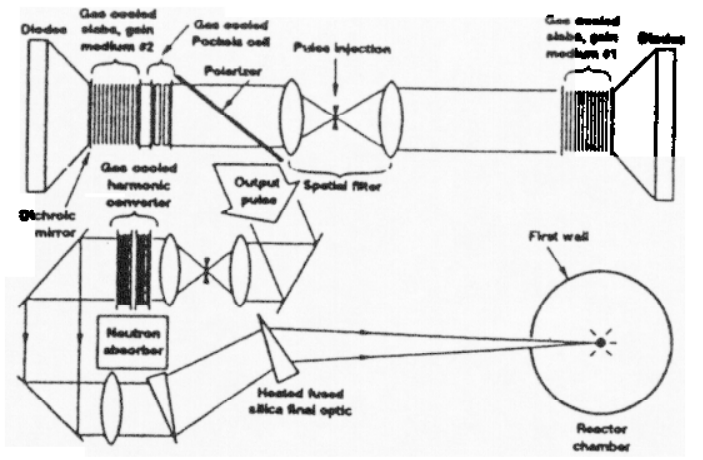

Fig. 7. One of 345 beam lines of a diode-pumped solid state laser used in a power plant.

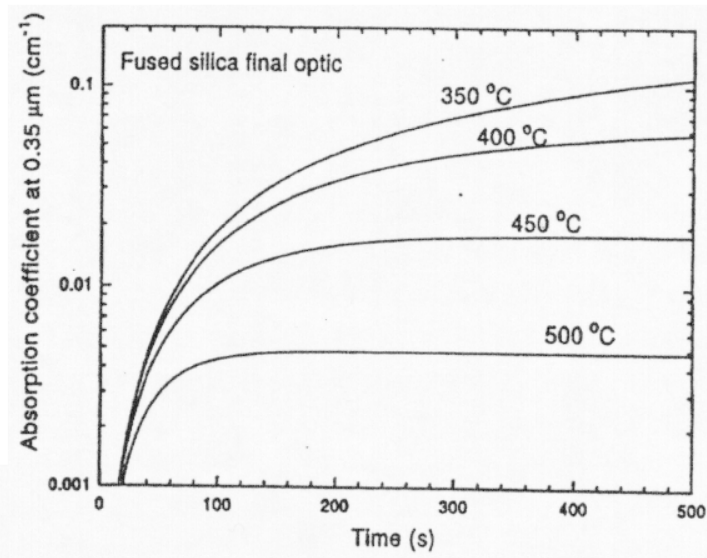

Fig. 8. Steady-state absorption of fused silica at $\lambda=0.35 \mu \mathrm{m}$ arising from gamma/neutron induced defects for $50 \mathrm{kRad} / \mathrm{sec}$.

\section{SUMMARY}

We have embarked on the development and construction of a meaningful plasma-physics "target-shooter", based on the diode-pumped gas-cooled $\mathrm{Yb}$ :S-FAP solid state laser approach. This effort represents the first paradigm-shift in the solid-state laser technology employed since its inception in the 1970s. Substantive enhancements in efficiency $(0.5 \% \rightarrow$ $10 \%)$, repetition-rate $\left(10^{-4} \mathrm{~Hz} \rightarrow 10 \mathrm{~Hz}\right)$ and reliability $10^{5} \rightarrow$ $10^{10}$ shots) are thought to be forthcoming, based on advanced solid-state lasers for inertial fusion energy. 


\section{REFERENCES}

[1] J. L. Emmett, W. F. Krupke, AND J. B. Trenholme, "Future development of high-power solid-state laser systems", Sov. J. Quantum Electron, vol 13, pp. 1-23, January 1983.

[2] C. D. Orth, S. A. Payne, and W. F. Krupke, "A diode pumped solid state laser driver for inertial fusion energy", Nuclear Fusion, vol. 36, pp 75-118, 1996.

[3] C. D. Marshall, L. K. Smith, S. B. Sutton, M. A. Emanuel, K. I. Shaffers, S. T. Mills, S. A. Payne, and W. F. Krupke, "Diode-pumped gas-cooled-slab laser performance ", in OSA TOPS on Advanced Solid-State Lasers, S. A. Payne and C. Pollock, Eds., Washington, D.C., 1996, pp 208-212.

[4] C. D. Marshall, S. A. Payne, L. K. Smith, H. T. Powell, W. F. Krupke, and B. H. T. Chai, “1.047- $\mu \mathrm{m}$ $\mathrm{Yb}: \mathrm{Sr}^{3}\left(\mathrm{PO}_{4}\right)_{3} \mathrm{~F}$ energy storage optical amplifier", IEEE J. Selected Tiopics in Quantum Electron., vol 1, pp. 6777. April 1995.

[5] L. D. DeLoach, S. A. Payne, L. L. Chase, L. K. Smith, W. L. Kway, and W. F. Krupke, "Evaluation of sbsorption and emission properties of $\mathrm{Yb}^{3+}$ doped crystals for laser applications", IEEE J. Quantum Electron., vol 29. pp. 1179-1191, April 1993.

[6] S. A. Payne, L. L. Chase, L. K. Smith, W. L. Kway, and W. F. Krupke, "Infrared cross-section measurements for crystals doped with $\mathrm{Er}^{3+}, \mathrm{Tm}^{3+}$ and $\mathrm{Ho}^{3+\cdots}$, IEEE J. Quantum Electron., vol 28, pp. 2619-2630, November 1992.

[7] S. A. Payne and C. D. Marshall, "Taking lasers beyone the National Ignition Facility", in Science and Technology Review, 13. Failor and R. Upadhye, Eds., National Technical Information Service, Springfield, VA., September 1996, pp. 4-11.

[8] C. D. Marshall, J. A. Speth, and S. A. Payne, "Induced optical absorption in gamms, neutron and ultraviolet irradiated fused quartz and silica", J. Non-Cryst. Solids, vol. 212, pp. 59-73, 1997.

[9] T. Lehecka, S. Bodner, A. V. Deniz, A. N. Mostovych, S. P. Obenschain, C. J. Pawley, and M. S. Drunko, J. Fusion Energy, vol. 10, pp. 301-303, 1991.

This work was performed under the auspices of the U.S. DOE by LLNL under Contract No. W-7405-ENG-48. 


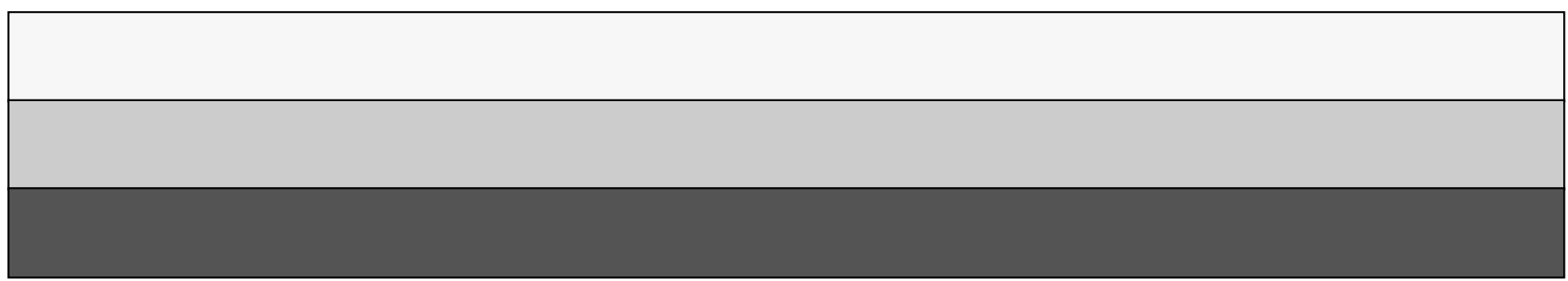

